\title{
Use of flow volume curve to evaluate large airway obstruction
}

\author{
Malay Sarkar ${ }^{1}$, Irappa V. Madabhavi ${ }^{2}$, Shailee P. Mehta ${ }^{3}$, Swadeshkumar Mohanty ${ }^{4}$ \\ ${ }^{1}$ Department of Pulmonary Medicine, Indira Gandhi Medical College, Shimla, Himachal Pradesh; ${ }^{2}$ Department of \\ Medical and Pediatric Oncology and Hematology, Kerudi Cancer Hospital, Bagalkot, Karnataka; ${ }^{3}$ Department of \\ Pathology, Gujarat Cancer and Research Institute, Ahmedabad, Gujarat; ${ }^{4}$ Pulmonary Medicine, Indira Gandhi \\ Medical College, Shimla, Himachal Pradesh, India
}

\begin{abstract}
The flow volume loop (FVL) is a graphic display of airflow against lung volumes at different levels obtained during the maximum inspiratory and expiratory maneuver. It is a simple and reproducible method of lung function assessment. A narrative review was performed according to the Preferred Reporting Items for Systematic Reviews and Meta-Analysis (PRISMA) guidelines. PubMed, EMBASE, Ovid MEDLINE and CINAHL databases were queried and reviewed for studies pertinent to the various FVLs
\end{abstract}

Correspondence: Dr. Irappa Vithoba Madabhavi, Department of Medical and Pediatric Oncology, Kerudi Cancer Hopital, Bagalkot 587103, Karnataka, India.

Tel.+91.7619501323. E-mail: irappamadabhavi@gmail.com

Key words: Flow-volume loop, upper airway obstruction, restrictive ventilatory defect.

Author contributions: MS, conceived and designed the experiment, made critical revisions, and approved the final version; MS, IM, SPM, $\mathrm{SM}$, analyzed the situation and wrote the first draft of the manuscript; MS, IM, SPM, contributed to the writing of the manuscript; MS, IM reviewed and agreed with the manuscript results and conclusions; MS, SM, prepared the figure and table; MS, IM, SPM, SM, jointly developed the structure and arguments for the paper. All authors reviewed and approved the final manuscript before submission.

Conflict of interest: The authors declare that they have no competing interests, and all authors confirm accuracy.

Ethics approval: not applicable.

Received for publication: 25 may 2021.

Accepted for publication: 16 Janaury 2022.

Publisher's note: All claims expressed in this article are solely those of the authors and do not necessarily represent those of their affiliated organizations, or those of the publisher, the editors and the reviewers. Any product that may be evaluated in this article or claim that may be made by its manufacturer is not guaranteed or endorsed by the publisher.

${ }^{\text {CC}}$ Copyright: the Author(s), 2022

Licensee PAGEPress, Italy

Monaldi Archives for Chest Disease 2022; $92: 1947$

doi: 10.4081/monaldi.2022.1947

This article is distributed under the terms of the Creative Commons Attribution-NonCommercial International License (CC BY-NC 4.0) which permits any noncommercial use, distribution, and reproduction in any medium, provided the original author(s) and source are credited. abnormalities and their mechanisms from January 2020 to December 2020. We used the following search terms; flow-volume loop, upper airway obstruction, Obstructive airway disease, and spirometry. Assessing the shape of the flow-volume loop is particularly helpful in diagnosing and localizing upper airway obstruction. They are also helpful in identifying bronchodilator response to treatment. Characteristic FVLs is also seen in patients with obstructive or restrictive lung disorders. Spirometry should be interpreted using the absolute values for flows and volumes as well as the flow volume and volume time curves.

\section{Introduction}

Hyatt and Black defined the maximum expiratory flow-volume (MEFV) curve as a plot of maximal expiratory flow against volume while performing the FVC maneuver [1]. The term maximal FVL is used when maximal forced expiration and maximal forced inspiration are obtained graphically. This loop is more useful as it provides information about the inspiratory limb of the FVL, therefore, can detect extrathoracic upper airway obstruction. The 2005 American Thoracic Society/European Respiratory Society guideline recommends examining the FVL for evidence of intrathoracic or extrathoracic upper airway obstruction [2]. Tidal flow-volume loop is obtained during the quite breathing maneuver. Miller and Hyatt in a seminal study described the three distinct patterns of abnormalities in the FVL: variable extrathoracic, variable intrathoracic, and fixed upper airway obstruction [3].

\section{Methods}

A narrative review was performed according to the Preferred Reporting Items for Systematic Reviews and Meta-Analysis (PRISMA) guidelines. In this narrative review PubMed, EMBASE, Ovid MEDLINE and CINAHL databases were queried and reviewed for studies pertinent to the various FVLs abnormalities and their mechanisms from January 2020 to December 2020 with search terms viz; flow-volume loop, upper airway obstruction, Obstructive airway disease, and spirometry.

\section{Normal physiology}

The FVL is generated in real-time while performing the forced vital capacity (FVC) and forced expiratory volume in one second 
$\left(\mathrm{FEV}_{1}\right)$ test maneuvers. In the FVL, the volume is displayed on the horizontal axis (X-axis) and the rate of airflow on the vertical axis (Y-axis). Figure 1 is depicting the normal flow-volume curve. Conventionally, the expiratory flow in the FVL is plotted upward and the inspiratory flow is plotted downward. The procedure involves the following steps: First, the subject is advised to take tidal breathing for several breaths followed by a maximal inspiration to total lung capacity (TLC). Then the subject is asked to pursue a forced, quick maximal expiration to residual volume followed by a rapid inhalation back to TLC. The subject may also be asked to empty their lungs first, and then take in a quick full inspiration, followed by a full expiration [4]. The procedure should be repeated for a minimum of three maneuvers. Initially, a maximal expiratory flow is obtained shortly after the onset of expiration (exhalation of the first $25 \%$ of the vital capacity) [5], which are called the peak expiratory flow (PEF). The flow can be increased by an increased effort at this lung volume. The PEF is thus effortdependent and is expressed as liters per minute. The maximal flow subsequently decreases with the reduction in lung volumes. This part of the curve which occurs in the remaining $75 \%$ of the vital capacity, is effort-independent as the flow cannot exceed the limit of maximal flow despite greater effort [6]. The flow-limiting feature can be explained by the equal pressure point (EPP) theory. It depends on pleural pressure, elastic recoil pressure, and airway pressure. Airway pressure normally falls along the airway from the alveolus to the mouth. Within the airways, there is a point where pleural pressure equals the pressure within the airways. This point is called the EPP [7]. Further downstream, the airway pressure falls below the pleural pressure, resulting in a narrowed airway and the development of flow-limitation. The elastic recoil pressure which normally keeps the airways open during expiration, decreases with a decreased lung volume, resulting in limitation of flow [8]. The inspiratory limb is effort-dependent also. Vital capacity is meas-

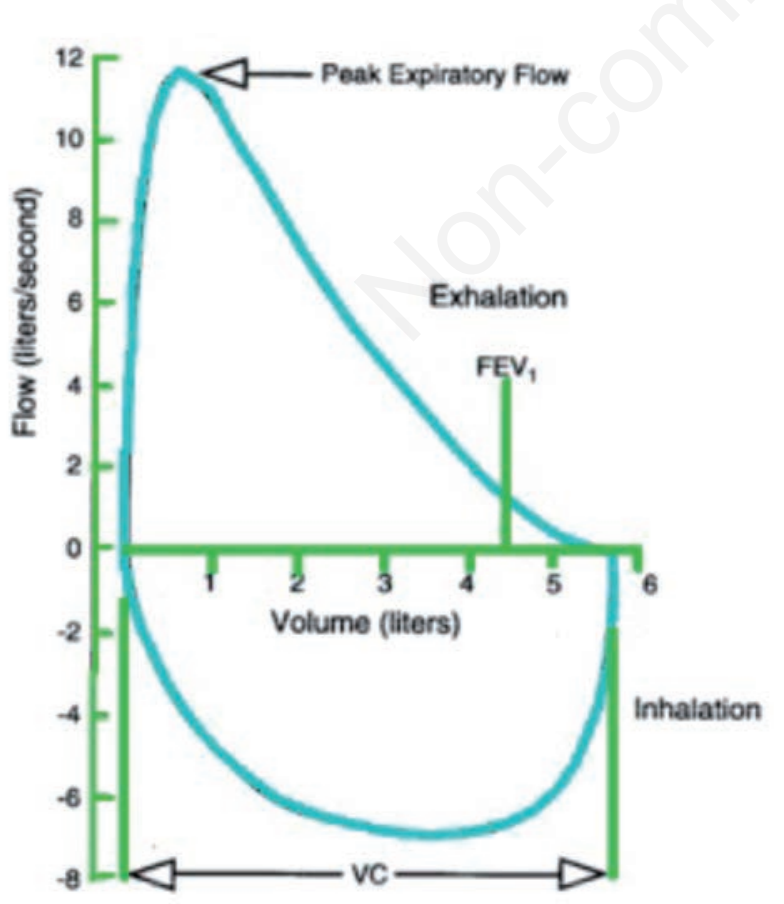

Figure 1. The normal flow-volume curve. FEV1, forced expiratory volume in one second; VC, vital capacity. ured by the distance between the start and the end of loops on the $\mathrm{x}$-axis. Two ratios are also calculated from the maximal flow-volume loop. These include the Mid-vital capacity ratio $\left(\mathrm{FEF}_{50} / \mathrm{FIF}_{50}\right)$ and Empey's index. Empey's index consists of the ratio of forced expiratory volume in $1 \mathrm{~s}\left(\mathrm{FEV}_{1}\right)$ and peak expiratory flow (PEF) [9]. Empey's index greater than 10 is suggestive of upper airway obstruction [9]. In upper airway obstruction, peak flows are affected early, while the FEV1 is affected only at a later stage $[5,10]$. Thus, $\mathrm{FEV}_{1}$ percent predicted may be normal. Abnormalities of the contour of the FVL are more helpful in suggesting upper airway obstruction. However, FVL has low sensitivity in detecting upper airway obstruction as it becomes abnormal only after the tracheal lumen is $<8 \mathrm{~mm}$ ( $\geq 80 \%$ tracheal narrowing) [10]. The sensitivity and specificity of the FVL in detecting central airway obstruction is $88.9 \%$ and $91.3 \%$ using the quantitative criteria and $30.6 \%$ and 93.5\% using qualitative criteria respectively [11].

\section{Upper airway obstruction}

The airway may be divided functionally into the following three levels based on location and diameter. The peripheral small airways are $2 \mathrm{~mm}$ or less in diameter. The larger or major airways extend from $2 \mathrm{~mm}$ diameter up to the main carina [12]. The upper airways extend from the nose or mouth up to the carina. The upper or central airways are further divided based on whether it is above or below the thoracic inlet. The extrathoracic portion of the upper airways is above the thoracic inlet, while the intrathoracic portion of the upper airway extends from the carina to the thoracic inlet superiorly. The thoracic inlet is situated at the level of the first thoracic vertebra and is 1 to $3 \mathrm{~cm}$ above the suprasternal notch. The three patterns are fixed obstruction, variable extrathoracic obstruction, and variable intrathoracic obstruction. Several variables influence the effects of the upper airway obstruction; the size of the airway at the site of the obstruction, the location of the obstruction, the nature of the lesion, and phase of respiration [12]. The central airway obstruction is classified into a fixed and variable obstruction [6]. It determines the impact of transmural pressure on airway cross-sectional area during the respiratory cycle. Transmural pressure is defined by the difference between the intratracheal pressure and the external pressure. The external pressure is different at different locations. Figure 2 is showing the various pressures acting over the upper airway.

In the case of extrathoracic upper airways, the external pres-

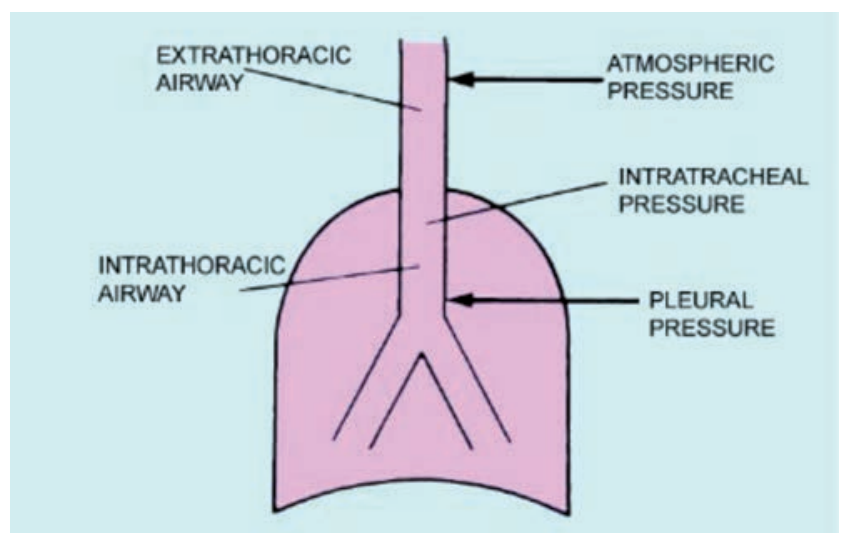

Figure 2. The various pressures acting over the upper airway. 
sure is the atmospheric pressure, whereas, in the case of the intrathoracic upper airway, it is the pleural pressure. A positive transmural pressure (external pressure $>$ intratracheal pressure) tends to narrow the airways, whereas a negative transmural pressure (external pressure $<$ intratracheal pressure) tends to open the airways [12]. In fixed obstruction, the airway lumen is relatively resistant to changes in transmural pressure with maximum inspiration and expiration, leading to a decreased flow equally during both phases of the respiratory cycle irrespective of whether the obstruction is extrathoracic or intrathoracic. The variable obstructions show changes in the airway lumen in response to changes in transmural pressure differences generated during the respiratory cycle. Therefore, the lesions narrow and the flow decreases excessively during one or the other phases of respiration. In patients with upper airway obstruction, reduction of flow mainly occurs in high lung volumes whereas, in COPD, reduction of flow mainly involves the effort-independent part [13] (Table 1).

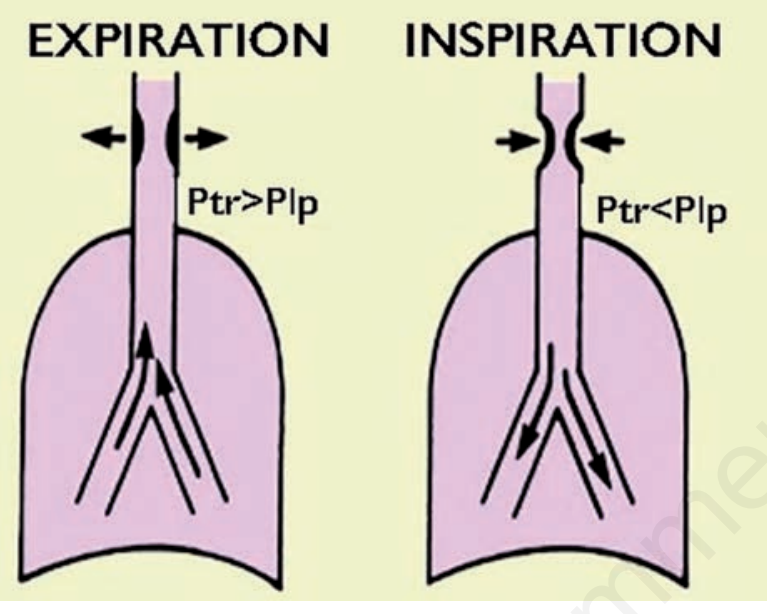

Figure 3. The mechanisms of variable extrathoracic upper airway obstruction. The extrathoracic trachea is exposed to the compressive force of atmospheric pressure. During a forceful inspiratory maneuver, the intratracheal pressure becomes significantly lower than the atmospheric pressure. This narrows the airways during inspiration. This explains the presence of plateau on the inspiratory limb of the flow volume loop. During forced expiration, intratracheal pressure becomes markedly positive and exceeds the surrounding atmospheric pressure, thereby reduces the obstruction. Ptr, tracheal pressure; Ppl, pleural pressure.

\section{Variable extrathoracic obstruction}

The extrathoracic upper airway lesion is above the suprasternal notch. In patients with a variable extrathoracic obstruction, there is flattening or truncation of the inspiratory limb of the flow-volume loop with a significant reduction in inspiratory flow. The expiratory limb is relatively normal. The $\mathrm{FEV}_{1}$ is also significantly greater than the $\mathrm{FIV}_{1}$ and the mid-vital capacity ratio $\left(\mathrm{FEF}_{50} / \mathrm{FIF}_{50}\right)$ is higher than one [5]. The obstruction occurs in the inspiratory phase. This pattern is most commonly caused by vocal cord paralysis, vocal cord neoplasm, extrathoracic goiter, tracheomalacia, and tumors in the neck [14]. However, an abnormal inspiratory curve may occur on routine spirometry due to a poor inspiratory effort [15]. The FVL in bilateral vocal cord paralysis also shows an amputated peak expiratory flow, an expiratory plateau, and flow oscillations along with flattening or truncation of the inspiratory limb [16]. Bahrainwala et al. reported a unique pattern of FVL abnormalities in asthmatics with VCD. There were a sudden decrease and rise in expiratory flow and on laryngoscopy, there is adduction followed by the abduction of the vocal cords during mid-expiration [17].

\section{Mechanisms}

The extrathoracic trachea is surrounded by the atmosphere, thereby is exposed to the compressive force of atmospheric pressure. During a forceful inspiratory maneuver, the intratracheal pressure becomes significantly lower than the atmospheric pressure. Moreover, due to Bernoulli's effect, intraluminal pressure falls further associated with an accelerated flow as air moves past the obstruction towards the alveoli. The decreased intraluminal pressure further narrows the airways during inspiration. This explains the presence of plateau on the inspiratory limb of the FVL. During forced expiration, intratracheal pressure becomes markedly positive and exceeds the surrounding atmospheric pressure, thereby reduces the obstruction. Figure 3 is showing the mechanisms of variable extrathoracic upper airway obstruction. Therefore, in patients with extrathoracic variable upper airway obstruction, obstruction manifests during inspiration resulting in the development of plateau on the inspiratory limb. Figure 4 is showing the FVL pattern of variable extrathoracic upper airway obstruction.

Table 1. The features of upper airway obstruction.

\begin{tabular}{|c|c|c|c|c|}
\hline Site of obstruction & Impact on & Impact on & Typical & Conditions responsible \\
\hline & expiratory limb & inspiratory limb & nomenclature & \\
\hline $\begin{array}{l}\text { Upper airway above } \\
\text { the sternal notch }\end{array}$ & Nil & Flattening/ truncation & $\begin{array}{l}\text { Variable extrathoracic } \\
\text { upper airway obstruction }\end{array}$ & $\begin{array}{l}\text { Vocal cord paralysis, vocal cord neoplasm, } \\
\text { extrathoracic goiter, tracheomalacia, and tumors } \\
\text { in the neck }\end{array}$ \\
\hline $\begin{array}{l}\text { Upper airway below } \\
\text { the sternal notch }\end{array}$ & Flattening/ truncation & Nil & $\begin{array}{l}\text { Variable intrathoracic } \\
\text { upper airway obstruction }\end{array}$ & $\begin{array}{l}\text { Tracheal tumors, tracheobronchomalacia, } \\
\text { Wegener granulomatosis, and relapsing } \\
\text { polychondritis }\end{array}$ \\
\hline $\begin{array}{l}\text { Extrathoracic } \\
\text { or intrathoracic }\end{array}$ & Flattening/ truncation & Flattening/ truncation & $\begin{array}{l}\text { Fixed upper airway } \\
\text { obstruction }\end{array}$ & $\begin{array}{l}\text { Tracheal stenosis, tumors at any level of upper } \\
\text { airways causing fixed obstruction }\end{array}$ \\
\hline
\end{tabular}




\section{Variable intrathoracic obstruction}

Variable intrathoracic obstruction is generally due to malignant causes, whereas the variable extrathoracic obstruction is usually due to benign causes $[5,18]$. The FVL in variable intrathoracic airway obstruction is characterized by flattening or truncation in the expiratory limb. The inspiratory limb is normal [19]. The plateau in expiration may occur after an initial spike and a slope may be seen in the terminal effort-independent part. However, in COPD patients, expiratory flow decreases throughout the entire FVC [3]. Miller and Hyatt also described a pattern of double hump during expiration. It may occur if the narrow areas of the airways move from an intrathoracic location to an extrathoracic location during later of part of the forced vital capacity maneuver. The selective

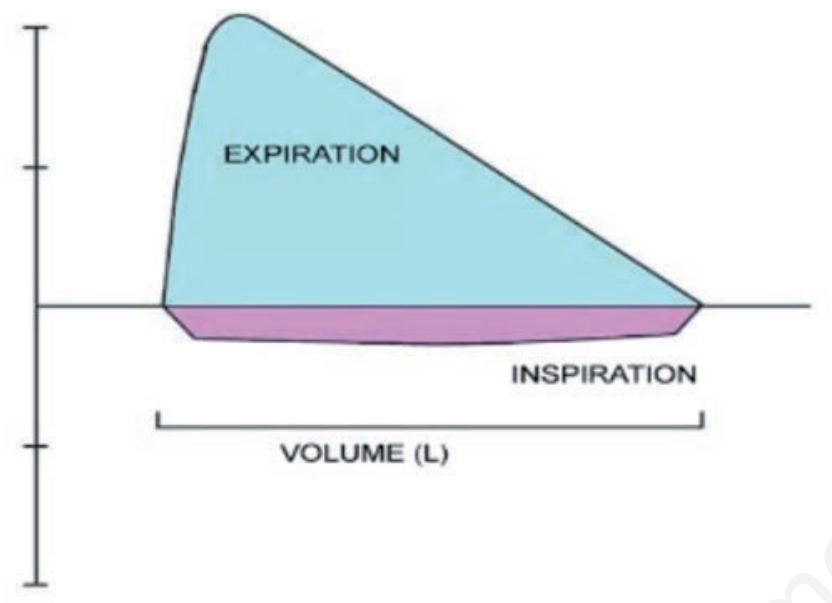

Figure 4. The flow volume loop pattern in variable extrathoracic upper airway obstruction.

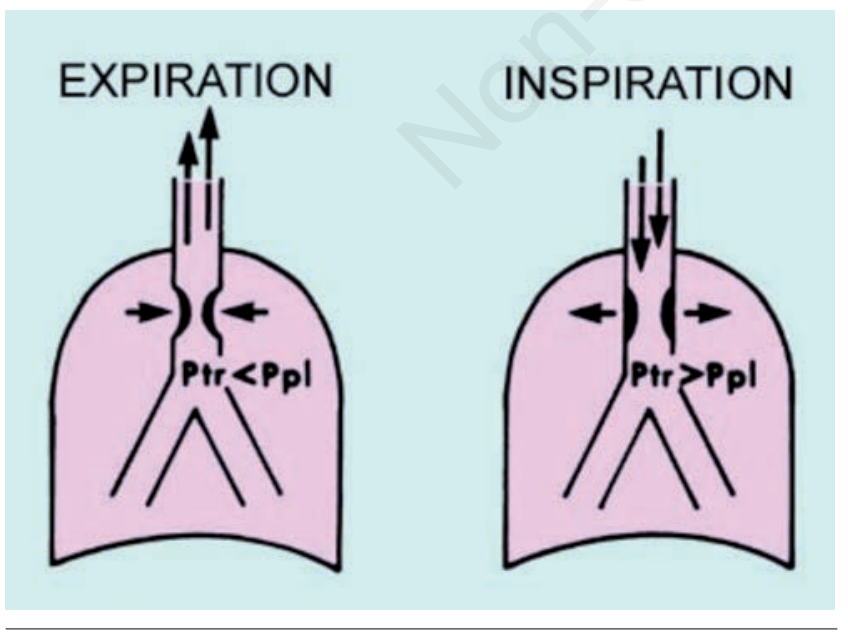

Figure 5. The mechanism of variable intrathoracic upper airway obstruction. During forced inspiration, the negative pleural pressure pulls the airway outward and reduces obstruction. However, during forced expiration, the intrapleural pressure becomes markedly positive and greater than the intratracheal pressure, resulting in compression of the obstructed segment. It causes truncation of the expiratory limb of the flow volume loop. reduction in expiratory flow causes the mid-vital capacity ratio $\left(\mathrm{FEF}_{50} / \mathrm{FIF}_{50}\right)$ to become less than 0.3 [5]. The $\mathrm{FEV}_{1}$ is also significantly lower than the $\mathrm{FIV}_{1}$. Various causes of variable intrathoracic obstruction are tracheal tumors, tracheobronchomalacia, Wegener granulomatosis, and relapsing polychondritis.

\section{Mechanisms}

The intrathoracic upper airway is surrounded by pleura and is influenced by pleural pressure $(\mathrm{Ppl})$. Transmural pressure of the intrathoracic upper airway is determined by the Ppl and intra-tracheal pressure (Ptr). During forced inspiration, the negative pleural pressure pulls the airway outward and reduces obstruction. Therefore, the inspiratory limb is normal. However, during forced expiration, the intrapleural pressure becomes markedly positive and greater than the intratracheal pressure, resulting in compression of the obstructed segment. The narrowing is further augmented by the development of venture effect and turbulency cephalad to the obstruction [20]. The plateau suggests a constant flow through the narrow segment which has achieved its minimal size. Figures 5 and 6 are showing the mechanism and FVL pattern of variable intrathoracic upper airway obstruction.

\section{Fixed upper airway obstruction}

Fixed upper airway obstruction is relatively resistant to transmural pressure changes. It manifests as a constant degree of obstruction during the respiratory cycle irrespective of the location within the airways. The fixed lesion can be extrathoracic or intrathoracic. The most common examples are stricture due to previous endotracheal intubation [5]. A fixed lesion is characterized by the truncation or flattening of both inspiratory and expiratory limbs of the FVL. In fixed obstruction, the airway diameter at the site of the narrowed segment remains unaltered during both inspiration and expiration as the transmural pressure changes do not affect the airway caliber at the site of the stenosis. Plateau on the

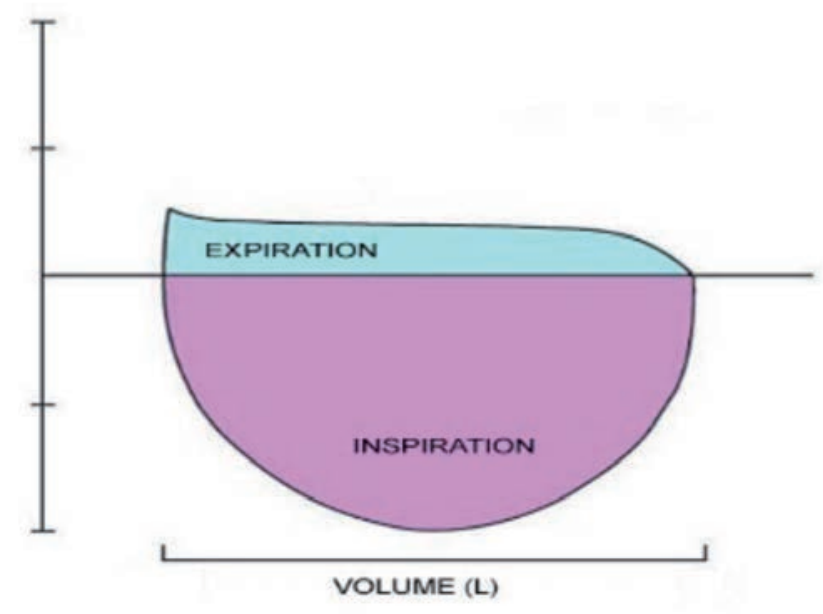

Figure 6. The FVL pattern of variable intrathoracic upper airway obstruction. 
expiratory limb is seen near the effort-dependent portion (near TLC) with little change near RV. The inspiratory limb shows a plateau around $50 \%$ of vital capacity [3]. The flattening of both the inspiratory and expiratory limb is known as the "box pattern." The mid-vital capacity ratio $\left(\mathrm{FEF}_{50} / \mathrm{FIF}_{50}\right)$ is around one. The plateaus may show rapid oscillations due to turbulency. Figures 7 and 8 are showing the mechanism and FVL pattern of fixed upper airway obstruction.

\section{Flow volume loop in unilateral main-stem obstruction}

Unilateral main-stem bronchial obstruction can occur in many conditions and shows a typical biphasic flow-volume loop. Various physiological abnormalities of unilateral main-stem bronchial obstruction have been described in the literature. Gelb et al. published the FVL abnormalities of 11 patients with unilateral, main stem bronchial obstruction before and after treatment with NdYAG laser or surgical resection [21]. The FVL pattern in three patients with associated emphysema showed an upward concavity on the expiratory limb; a pattern consistent with obstructive airway disease both before and after treatment. The FVL in the other eight patients showed a restrictive ventilator pattern with a normal slope of the expiratory limb. After laser or surgical treatment, all patients demonstrated improvement in the FVLs. Therefore, the predominant pattern in Gelb et al. series was restrictive pattern. Gascoigne et al first demonstrated the characteristic bi-phasic flow-volume loop in two patients with unilateral mainstem bronchial obstruction [22]. They reported the presence of an end-inspiratory tail in the inspiratory limb and a biphasic shape in the expiratory limb. The biphasic component includes a normal initial curvature and a straight-line appearance in the later part of expiration. Anzueto et al. reported similar biconcave pattern in a patient who developed bronchial stenosis after single lung transplantation [23]. Neagos et al. observed another feature of unilateral main-stem bronchial
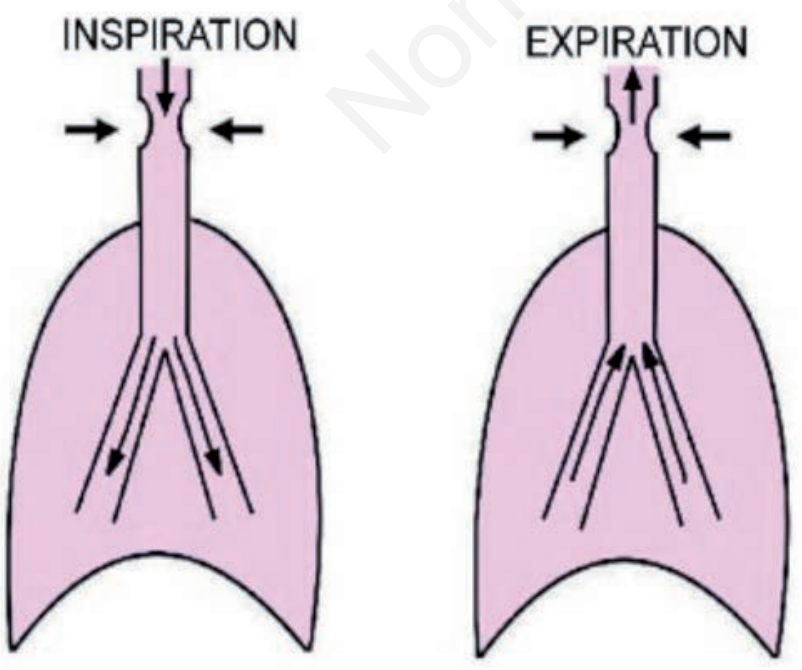

Figure 7. The mechanism of fixed upper airway obstruction. In fixed obstruction, the airway diameter at the site of the narrowed segment remains unaltered during both inspiration and expiration. It causes truncation of both the limbs of flow volume loop. obstruction developed after single lung transplant in patients with severe emphysema [24]. Flattening or plateau was seen in the early part of the expiratory loop of the flow-volume curve. Figure 9 is showing the biconcave pattern of FVL.

\section{Mechanism of biconcave pattern}

The biphasic pattern in unilateral obstruction of the main bronchus can be explained by the "two compartments" hypothesis

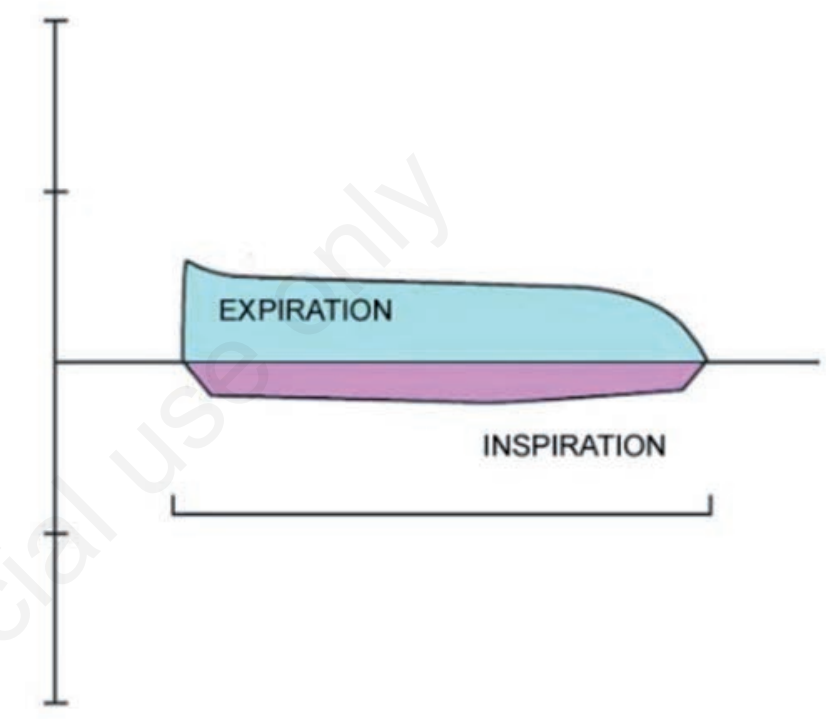

Figure 8. The flow volume loop pattern of fixed upper airway obstruction.

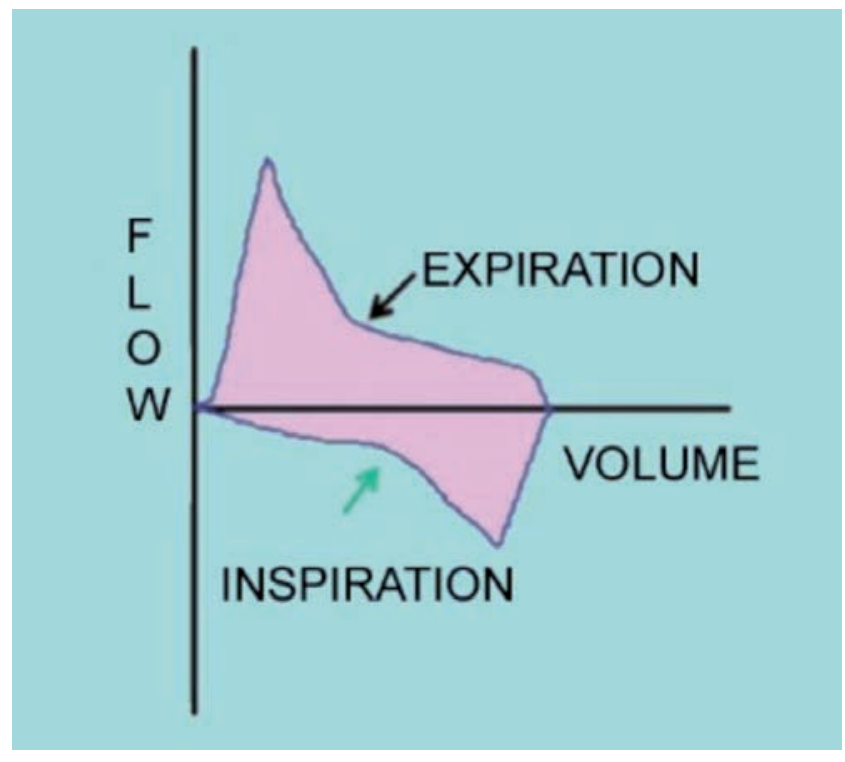

Figure 9. The biconcave flow volume loop pattern of unilateral main stem bronchus obstruction. 
[25]. The two compartments are the native lungs which may be diseased also and the transplanted lungs. They have different respiratory time constants. The two compartments of the lungs show asymmetric filling and emptying. The native lung will fill and empty more rapidly than the transplanted lung with main-stem bronchial stenosis. Therefore, the initial portion of the FVL represents air movement from and to the native lungs and the later portion are from the transplanted lung. The air movement from the transplanted lung is slower which explains the long flat tail on the inspiratory and expiratory limb [23]. Inspiratory tail is characteristic of unilateral mainstem bronchial obstruction as in condition of generalized airway obstruction, inspiratory tail does not occur [22]. The bi-phasic flow-volume loop has been reported in the following conditions: granulomatosis with polyangiitis, single lung transplantation, developmental cartilaginous ridge, Macleod's syndrome, sarcoidosis, tracheobronchomalacia, bronchogenic carcinoma and amyloidosis [22,26-28].

\section{Flow oscillations or saw-tooth appearance}

The saw-tooth sign is seen in patients with obstructive sleep apnea and Parkinson's diseases [29,30]. Sander at al. first described this sign in awake patients with upper airway obstruction associated with obstructive sleep apnea syndrome (OSA) [29]. Saw-tooth sign is characterized by regular oscillations in either the forced inspiratory or forced expiratory limb of a maximal flowvolume loop. The saw-tooth pattern was defined as three or more consecutive peaks and troughs occurring at regular intervals of no greater than $300 \mathrm{~cm}^{3}$, during the middle half of the vital capacity on spirometry. Vincken [31] on the other hand defined "saw-tooth" pattern as a sequence of alternating decelerations and accelerations of flow superimposed on the general contour of the flow-volume loop produced by an awake subject that is reproducible. It can involve both the inspiratory and/or expiratory limb of the flow-volume loop, irrespective of forced or tidal respiration. Several mechanisms have been proposed for the occurrence of saw-tooth pattern or flow oscillations: Intermittent changes in driving pressure due to abnormal phase activity of respiratory pump muscles, Changes in airway resistance, and abnormal phasic activity of the upper airway muscle $[31,32]$. Flow oscillations have been reported in obstructive sleep apnea syndrome, structural or functional disorders of the larynx, or neuromuscular diseases, and tracheobronchomalacia [31,33].

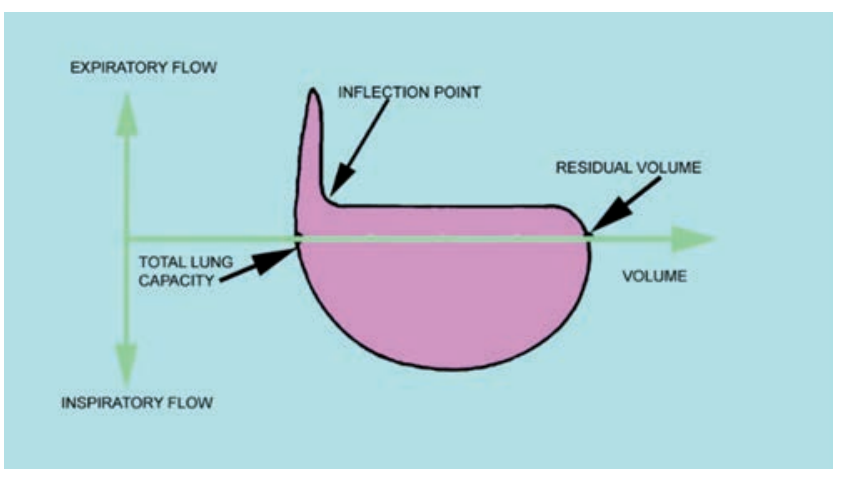

Figure 10. The flow volume loop pattern of COPD. There is a sharp decrease in expiratory curve with inflection point (arrow).

\section{Flow volume curves in peripheral airway obstruction}

Pathophysically, COPD is characterized by lung hyperinflation resulting from expiratory flow limitation (EFL). The EFL occurs due to airway obstruction and parenchymal destruction resulting in reduced elastic recoil of the lungs [34]. Reduced elastic recoil force leads to a decrease in expiratory flow and a higher than normal functional residual capacity (FRC). EFL causes air trapping and decreases the volume available for tidal expansion [35]. The FVLs in COPD typically show a decrease in the peak flow rate and upward concavity (curvilinearity) of descending limb of the expiratory curve. The loss of linearity is related to the severity of obstruction. The concavity of the expiratory limb is upward directed. Some COPD patients show biphasic morphology of the expiratory limb of FVL which is characterized by a low peak flow rate followed by a rapid fall in expiratory flow rate at a high lung volume and a plateau of low flow for the remaining phase [36-38]. Jayamanne et al. designated this pattern as a type-1 curve with the following features: an abrupt decrease in flow rate from peak flow to an inflection point [38]. The inflection point occurs at less than $50 \%$ of the peak flow rate. The inflection point occurs within the first $25 \%$ of expired vital capacity. The inspiratory limb of the curve is normal. This pattern is called the airway collapse pattern and is determined by the presence of dynamic airway collapse and loss of elastic recoil in patients with COPD. COPD patients with this pattern show a higher RV and FRC than patients with curvilinear pattern indicating more severe hyperinflation [39]. Jayamanne et al. also demonstrated the reversibility of airway collapse pattern in few patients which may be due to a reduction in central or peripheral airway resistance or an increase in lung elastic recoil, or any combination of these [38]. Diagnosis of upper airway obstruction in presence of COPD is often difficult. In the presence of severe COPD, FVL may not reveal even significant tracheal stenosis. Moreover, $\mathrm{FEV}_{1}$ is a poor indicator of large airway obstruction. Even variable intrathoracic upper airway obstruction is difficult to diagnose in patients with COPD as both can cause expiratory flow changes. However, in upper airway obstruction, the FVL becomes abnormal at high lung volume [40]. Figures 10 and 11 are showing the FVL patterns of COPD.

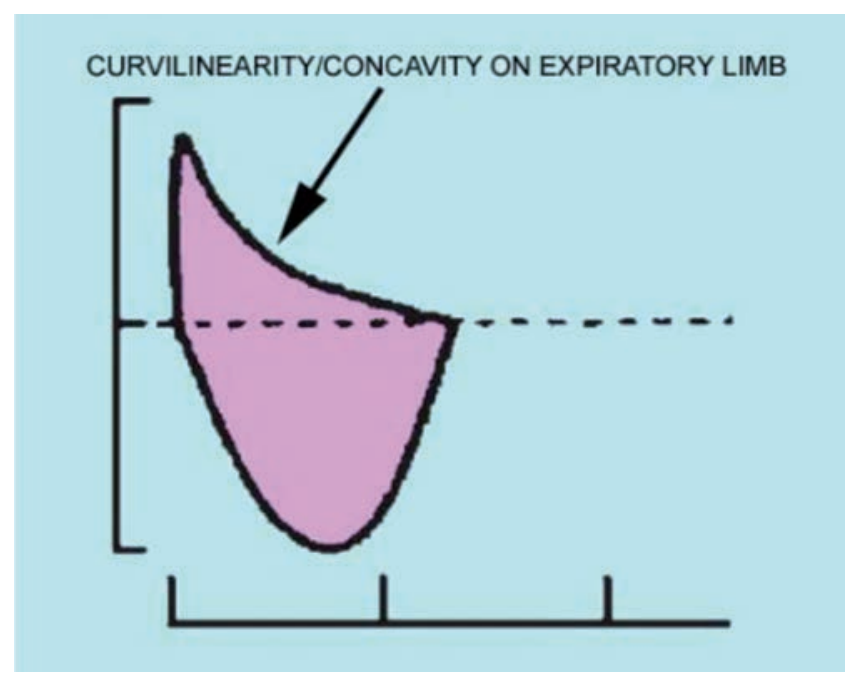

Figure 11. The flow volume loop pattern of COPD. There is curvilinearity on the expiratory limb. 


\section{Restrictive ventilatory defect}

Restrictive ventilatory disorders can be parenchymal (interstitial lung disease) or extraparenchymal (musculoskeletal disorders, obesity, etc.). Pathophysiologically, restrictive lung disorders are characterized by low lung volumes (increased TLC and VC) and an increased in lung elastic recoil with preserved or relatively enlarged airway dimensions. In the early stage of interstitial lung disease, the FVL may show abnormality even before the lung volumes are decreased [41]. The increased elastic recoil forces increase the initial exhaled airflow, resulting in a normal or increased PEF. Subsequently, the PEF is reduced as the exhaled lung volumes also decrease. The width of the FVLs is also reduced and the slope of the descending limb of expiratory loop also becomes steeper, resulting in a tall and narrow loop. It occurs due to an increase in the elastic recoil of the lung resulting in a super maximal expiratory airflow. However, in severe restriction, the FVLs become a miniature of the normal curve. This appearance of the curve in interstitial lung disease is called a witch's hat appearance. In chest wall restriction, PEF is decreased as the elastic recoil of the lung is normal. The slope of the curve is parallel to the predicted curve; making it a miniature of normal curve. Figure 12 is showing the FVL pattern of restrictive ventilatory defect.

Neuromuscular disorders produce a delayed, reduced and rounded peak and the curve looks convex in shape. Forced expiratory flow may show a sudden drop at end-expiration and the maximal inspiratory flow-volume curve may also show a flattened shape. Flow oscillations are also seen [42]. Flow oscillations can be due to vocal cord tremor or fasciculation of upper-airway muscles. Vincken et al. reported these abnormalities significantly more often in patients with neuromuscular disorders and bulbar muscle involvement than in those without bulbar muscle involvement [43].

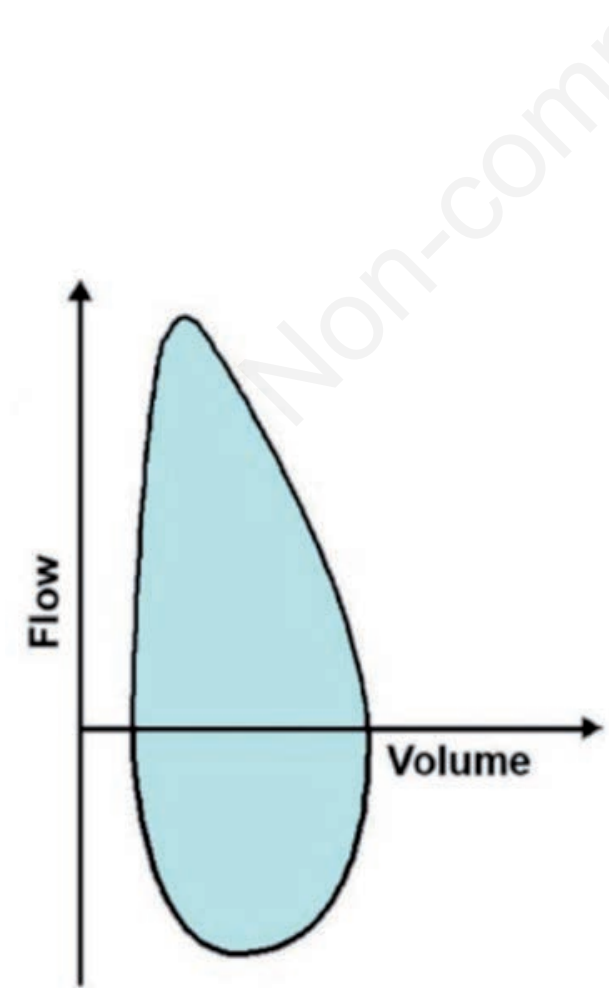

Figure 12. The flow volume loop pattern of restrictive ventilatory defect.

\section{Knee pattern}

The knee pattern is characterized by a convex inflection on the expiratory part of the FVL [44]. The knee pattern is a normal variant and is thought to be more common in non-smokers, especially young women [45]. The prevalence of the knee pattern declines with age, but it is more likely to persist in women [46]. Mead et al. hypothesized that knee pattern occurs due to the equal pressure point present in the lower trachea that limits the PEF causing a flatter slope just after the peak flow [47]. With aging and subsequent loss of lung parenchymal elastic recoil, the equal pressure point moves distal resulting in the disappearance of the knee pattern. Figure 13 is showing the FVL of knee pattern.

\section{Indices of upper airway obstruction}

1. Mid-vital capacity ratio $\left(\mathrm{FEF}_{50} / \mathrm{FIF}_{50}\right)$

2. Empey's index

$\mathrm{FEV}_{1}(\mathrm{ml}) / \mathrm{PEF}(\mathrm{L} / \mathrm{min})$

Empey's index greater than 10 is suggestive of upper airway obstruction.

Variable intrathoracic upper airway obstruction: $\mathrm{FEF}_{50} / \mathrm{FIF}_{50}<0.3$ Variable extrathoracic upper airway obstruction: $\mathrm{FEF}_{50} / \mathrm{FIF}_{50}>1$ Fixed upper airway obstruction: $\mathrm{FEF}_{50} / \mathrm{FIF}_{50}=1$

\section{Conclusions}

The flow-volume loop is a simple, easily available, and noninvasive test of lung function. Recognition of various patterns of FVL may help in identifying upper airway obstruction, peripheral airway obstruction, and restrictive ventilatory disorders. Upper airway obstructions are often misdiagnosed and mistreated as asthma and COPD. Recognizing these abnormalities may prevent delay in diagnosing upper airway obstruction. Detecting the change in the contour of the FVL should be assessed along with various quanti-

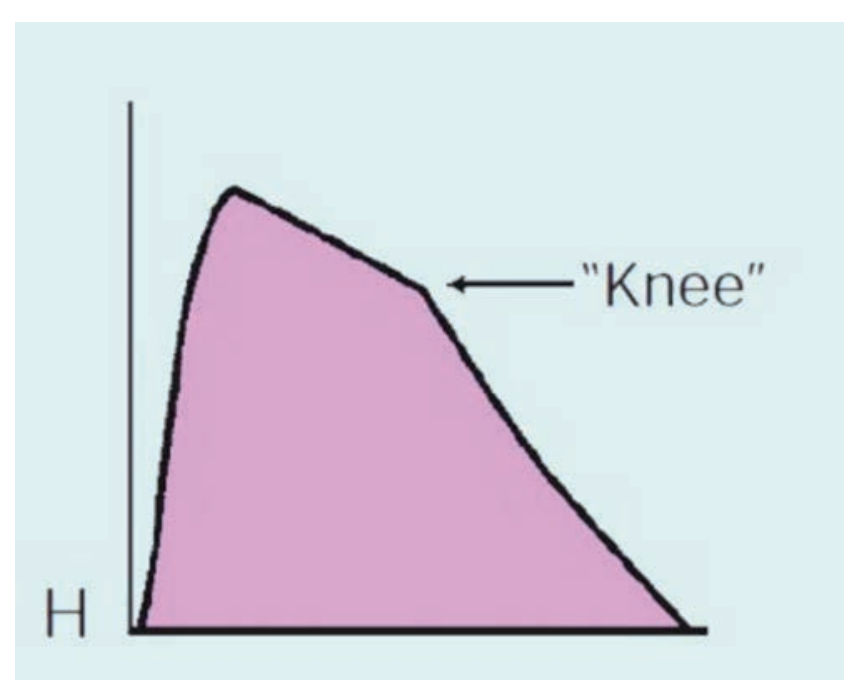

Figure 13. The flow volume loop of knee pattern. 
tative indexes in order to improve the sensitivity and specificity of the FVL in diagnosing upper airway obstruction. FVL also helps to identify the technical quality of the spirometry examination. FVL should be routinely assessed in the pulmonary function laboratory.

\section{References}

1. Hyatt RE, Black LF. The flow-volume curve. A current perspective. Am Rev Respir Dis 1973;107:191-9.

2. Pellegrino R, Viegi G, Brusasco V, et al. Interpretative strategies for lung function tests. Eur Respir J 2005;26:948-68.

3. Miller RD, Hyatt RE. Evaluation of obstructing lesions of the trachea and larynx by flow-volume loops. Am Rev Respir Dis 1973;108:475-41.

4. Moore VC. Spirometry: step by step. Breath 2012;8:233-40.

5. Kryger M, Bode F, Antic R, et al. Diagnosis of obstruction of upper and central airways. Am J Med 1976;61:85-93.

6. Lunn WW, Sheller JR. Flow volume loops in the evaluation of upper airway obstruction. Otolaryngol Clin North Am 1995;28:721-9.

7. Martin L. Pulmonary physiology in clinical practice: the essentials for patient care and evaluation. St Louis: Mosby Inc.; 1987.

8. Mead J, Turner JM, Macklem PT, et al. Significance of the relationship between lung recoil and maximum expiratory flow. J Appl Physiol 1967;22:95-108.

9. Empey DW. Assessment of upper airway obstruction. Br Med J 1972;3:503-5.

10. Miller RD, Hyatt RE. Obstructing lesions of the larynx and trachea: clinical and physiologic characteristics. Mayo Clin Proc 1969;44:145-61.

11. Raposo LB, Bugalho A, Gomes MJ. Contribution of flow-volume curves to the detection of central airway obstruction. J Bras Pneumol 2013;39:447-54.

12. Acres JC, Kryger MH. Clinical significance of pulmonary function tests: upper airway obstruction. Chest 1981;80:207-11.

13. Yernault Je, Englert M, Sergysels R, De Coster A. Upper airway stenosis: A physiologic study. Am Rev Respir Dis 1973;108:999-1000.

14. Stoller JK. Spirometry: a key diagnostic test in pulmonary medicine. Cleve Clin J Med 1992;59:75-8.

15. Sterner JB, Morris MJ, Sill JM, Hayes JA. Inspiratory flowvolume curve evaluation for detecting upper airway disease. Respir Care 2009; 54:461-6.

16. Bolliger CT, Sofko J, Maurer P, Perruchoud AP. The flow-volume loop in bilateral vocal cord paralysis. Chest 1993;104:1302-4.

17. Bahrainwala AH, Simon MR, Harrison DD, et al. Atypical expiratory flow volume curve in an asthmatic patient with vocal cord dysfunction. Ann Allergy Asthma Immunol 2001;86:439-43.

18. Guntupalli KK, Bandi V, Sirgi C, et al. Usefulness of flow volume loops in emergency center and ICU settings. Chest 1997;111:481-8.

19. Hyatt RE. Evaluation of major airway lesions using the flowvolume loop. Ann Otol Rhinol Laryngol 1975;84:635-42.

20. Aboussouan LS, Stoller JK. Diagnosis and management of upper airway obstruction. Clin Chest Med 1994;15:35-53.

21. Gelb AF, Tashkin DP, Epstein JD, et al. Physiologic characteristics of malignant unilateral mainstem bronchial obstruction: diagnosis and Nd-YAG laser treatment. Am Rev Respir Dis 1988;138:1382-5.
22. Gascoigne AD, Corris PA, Dark JH, Gibson GJ. The biphasic spirogram: a clue to unilateral narrowing of a mainstem bronchus. Thorax 1990;45:637-8.

23. Anzueto A, Levine SM, Tillis WP, et al. Use of flow volume loop in the diagnosis of bronchial stenosis after single lung transplantation. Chest 1994;105:934-6.

24. Neagos GR, Martinez FJ, Deeb GM, et al. Diagnosis of unilateral mainstem bronchial obstruction following single-lung transplantation with routine spirometry. Chest 1993;103:1255-8.

25. Roos CM, Braat MC. End-inspiratory flow reduction in the forced flow-volume curve as a sign of unilateral bronchial disease. Neth J Med 1985;28:378-82.

26. Agrawal A, Sahni S, Marder G, et al. Biphasic flow-volume loop in granulomatosis with polyangiitis related unilateral bronchus obstruction. Respir Investig 2016;54:280-3.

27. Jeong YG, Donohue JF. Unilateral bronchial occlusion in a patient with sarcoidosis and a bronchial anomaly. South Med J 1980;73:523-4.

28. Majid A, Sosa AF, Ernst A, et al. Pulmonary function and flowvolume loop patterns in patients with tracheobronchomalacia. Respir Care 2013;58:1521-6.

29. Sanders MH, Martin RJ, Pennock BE, Rogers RM. The detection of sleep apnea in the awake patient: The 'saw tooth' sign. JAMA 1981;245:2414-18

30. Schiffman PL. A "saw-tooth" pattern in Parkinson's disease. Chest 1985;87:124-6.

31. Vincken WG, Cosio MG. Flow oscillations on the flow-volume loop: clinical and physiological implications. Eur Respir J 1989;2:543-9.

32. Vincken WG, Gauthier SG, Dollfuss RE, et al. Involvement of upper-airway muscles in extrapyramidal disorders. A cause of airflow limitation. N Engl J Med 1984;311:438-42.

33. Garcia-Pachon E. Tracheobronchomalacia: a cause of flow oscillations on the flow-volume loop. Chest 2000;118:1519.

34. Das N, Topalovic M, Aerts JM, et al. Area under the forced expiratory flow-volume loop in spirometry indicates severe hyperinflation in COPD patients. Int J Chron Obstruct Pulmon Dis 2019;14:409-18.

35. Langer D, Ciavaglia CE, Neder JA, et al. Lung hyperinflation in chronic obstructive pulmonary disease: mechanisms, clinical implications and treatment. Expert Rev Respir Med 2014;8:731-49.

36. Campbell AH, Faulks LW. Expiratory airflow patterns in tracheobronchial collapse. Am Rev Respir Dis 1965;92:781-91.

37. Gandevia B. The spirogram of gross expiratory tracheobronchial collapse in emphysema. Q J Med 1963;32:23-31.

38. Jayamanne DS, Epstein H, Goldring RM. Flow volume curve contour in COPD: correlation with pulmonary mechanics. Chest 1980;77:749-57.

39. Murgu SD, Colt HG. Tracheobronchomalacia and excessive dynamic airway collapse. Respirology 2006;11:388-406.

40. Karkhanis VS, Joshi JM. Spirometry in chronic obstructive lung disease (COPD). J Assoc Physicians India 2012;60 Suppl:22-6.

41. Arora VK, Raghu S. Flow volume curves: clinical significance. Lung India 1996;XIV: 169-71.

42. Vincken W, Elleker G, Cosio MG. Detection of upper airway muscle involvement in neuromuscular disorders using the flow-volume loop. Chest 1986;90:52-7.

43. Vincken WG, Elleker MG, Cosio MG. Flow-volume loop changes reflecting respiratory muscle weakness in chronic neuromuscular disorders. Am J Med 1987;83:673-80. 
44. Hancox B, Whyte K. McGraw-Hill's pocket guide to lung function tests. North Ryde: McGraw-Hill; 2006.

45. Hyatt RE, Scanlon PD, Nakamura M. Interpretation of pulmonary function tests: A practical guide. Philadelphia: Lippincott-Raven; 2007.
46. Shin HH, Sears MR, Hancox RJ. Prevalence and correlates of a 'knee' pattern on the maximal expiratory flow-volume loop in young adults. Respirology 2014;19:1052.

47. Mead J. Expiratory flow limitation: a physiologist's point of view. Fed Proc 1980;39:2771-5. 